\title{
Biomimetic fabrication of calcium phosphate/chitosan nanohybrid composite in modified simulated body fluids
}

\author{
K. H. Park, S. J. Kim, M. J. Hwang, H. J. Song, Y. J. Park* \\ Department of Dental Materials and Medical Research Center for Biomineralization Disorders, School of Dentistry, \\ Chonnam National University, Gwangju 61186, Korea
}

Received 1 June 2016; accepted in revised form 11 August 2016

\begin{abstract}
In this study, nucleation and growth of bone-like hydroxyapatite (HAp) mineral in modified simulated body fluids (m-SBF) were induced on chitosan (CS) substrates, which were prepared by spin coating of chitosan on Ti substrate. The $\mathrm{m}$-SBF showed a two fold increase in the concentrations of calcium and phosphate ions compared to SBF, and the post$\mathrm{NaOH}$ treatment provided stabilization of the coatings. The calcium phosphate/chitosan composite prepared in $\mathrm{m}-\mathrm{SBF}$ showed homogeneous distribution of approximately $350 \mathrm{~nm}$-sized spherical clusters composed of octacalcium phosphate $\left(\mathrm{OCP} ; \mathrm{Ca}_{8} \mathrm{H}_{2}\left(\mathrm{PO}_{4}\right)_{6} \cdot 5 \mathrm{H}_{2} \mathrm{O}\right)$ crystalline structure. Chitosan provided a control over the size of calcium phosphate prepared by immersion in $\mathrm{m}-\mathrm{SBF}$, and post-NaOH treatment supported the binding of calcium phosphate compound on the Ti surface. Post-NaOH treatment increased hydrophilicity and crystallinity of carbonate apatite, which increased its potential for biomedical application.
\end{abstract}

Keywords: nanocomposites, mineralization, simulated body fluid (m-SBF), chitosan, calcium phosphate

\section{Introduction}

Extensive studies have been carried out for the development of a substance which is similar in composition and structure to minerals in the apatite group such as composite of calcium phosphate [1]. It provides better biocompatibility and the carbonate-containing hydroxyapatite (HAp) layer on its surface is similar to the bone apatite. In spite of excellent biocompatibility, its rheological strength is far less than that required for bone tissue engineering [2, 3]. Moreover, HAp powder tends to migrate from implant sites and it possesses no antimicrobial activity. It must be emphasized at this point that the successful design of a bone substitute material requires an appreciation of the structure of bone. Thus, the use of a hybrid composite that comprises natural biopolymer and calcium phosphate most aptly resembles the morphology and properties of natural bone. Natural biomate- rials such as collagen, chitosan, gelatin, and hyaluronic acid are currently tested as coating materials of implants for the regeneration of damaged and diseased tissues on the basis of their biocompatibility and mechanical properties [4-7]. Collagen and gelatin from partial hydrolysis of collagen are biocompatible, non-cytotoxic, with an ability to support cellular growth, and can be processed into a variety of forms. However, certain properties of collagen and gelatin have adversely influenced some of its usage: poor dimensional stability due to swelling in vivo, poor in vivo mechanical strength and low elasticity, the possibility of an antigenic response, and the high-cost of pure type I collagen [8]. CS is a linear polysaccharide obtained by deacetylation of naturally abundant chitin, a polysaccharide found in exoskeletons of crustaceans such as crabs and shrimp and cell walls of fungi [9]. CS is biocompatible, biodegradable, and

$\overline{{ }^{*} \text { Corresponding author, e-mail: yjpark@jnu.ac.kr }}$

C BME-PT 
antibacterial [10]. In view of these properties, it is expected that a composite containing both CS and HAp may have the properties of both materials, namely, antimicrobial activity (from CS) and osteoconductive property (from HAp). The organic matrix acts as a binder to keep HAp at the implant site and a size controller of calcium phosphate prepared in simulated body fluid (SBF), spontaneously forming the bone-like apatite layer tightly bonded to the substrates. In order to predict bioactivity and evaluate biomineralization, a SBF has been used $[11,12]$. The biomimetic method using SBF can prepare an apatite layer on a substrate without using special equipment or extremely high processing temperatures. If a material is bioactive, it has to form a biological hydroxyapatite layer on its surface when it is immersed in a SBF during a certain time [13]. Tachaboonyakiat et al. [14] used an alternate soaking method to form hydroxyapatite on/in chitosan matrices with partial enzymatic degradation treatment to yield a porous hybrid material. Conventionally, most of the CS/HAp composite microspheres have been prepared by mixing the pre-obtained HAp particles with the chitosan matrices under proper conditions. However, the inorganic HAp particles cannot be uniformly distributed with the chitosan matrix due to the nanoparticle agglomeration [15]. In this study, these limitations could be overcome by CS spin coating on the titanium substrate and then immersing in SBF for mimicking the extracellular matrix of the natural bone [16]. The advantage of spin coating is its ability to produce very uniform films quickly and easily from a few nanometers to a few microns in thickness. A calcium phosphate $(\mathrm{CaP})$ compound was formed in $\mathrm{m}-\mathrm{SBF}$ solution on a CS-coated titanium substrate. The composition and structure of the $\mathrm{CaP} / \mathrm{CS}$ composite are discussed in comparison with those of the apatite formed after post-NaOH treatment.

\section{Experimental}

Commercially pure titanium (cp-Ti) of ASTM Grade 2 (Daito Steel Co. Ltd., Japan) was used as a substrate in this study. It was cut to a $10 \mathrm{~mm}$ diameter disk with a thickness of $1 \mathrm{~mm}$. The disc was degreased with acetone and water, polished with up to \#2000 SiC paper and ultrasonically cleaned in ethanol and distilled water. CS flake with a molecular weight of about $520000 \mathrm{~g} \cdot \mathrm{mol}^{-1}$ was obtained from Sehwa
Co. (Yeosu, Korea). The degree of deacetylation was $85 \%$. CS solution was prepared by dissolving CS $(1 \mathrm{~g})$ in $1 \%$ acetic acid $(100 \mathrm{~mL})$ with stirring for $5 \mathrm{~h}$ to obtain a perfectly transparent solution. All the chemicals were purchased from Aldrich Chemical Corporation and used without further purification. Ultrathin films of CS with a thickness of about $20 \mathrm{~nm}$ were obtained by spin coating the solution of CS dissolved in $1 \%$ acetic acid onto the cp-Ti substrate at a spin speed of $5000 \mathrm{rpm}$ for $20 \mathrm{~s}$. The films were dried at $40^{\circ} \mathrm{C}$ for $20 \mathrm{~min}$ in dry oven and the process was repeated 2 times. Finally, the chitosan films were stored at $25^{\circ} \mathrm{C}$ in a vacuum oven.

Modified SBFs, which had a higher concentration of inorganic ions compared with that of Kokubo's SBF solution, were used to fabricate a precipitated $\mathrm{CaP}$ coating. The $\mathrm{m}-\mathrm{SBF}$ used in this study was prepared according to the literature [17]. In brief, the SBF solution contained the following reagents in distilled water: $141 \mathrm{mM} \mathrm{NaCl}, 4.0 \mathrm{mM} \mathrm{KCl}, 0.5 \mathrm{mM}$ $\mathrm{MgSO}_{4}, 1.0 \mathrm{mM} \mathrm{MgCl}_{2}, 4.2 \mathrm{mM} \mathrm{NaHCO}_{3}, 2.5 \mathrm{mM}$ $\mathrm{CaCl}_{2} \cdot 2 \mathrm{H}_{2} \mathrm{O}, 3.94 \mathrm{~g} / \mathrm{L}$ of Tris- $\mathrm{HCl}$ and $1.0 \mathrm{mM}$ $\mathrm{KH}_{2} \mathrm{PO}_{4}$. The m-SBF solution was prepared by increasing the concentrations of $\mathrm{CaCl}_{2}$ and $\mathrm{KH}_{2} \mathrm{PO}_{4}$ two times to those of SBF solution. The m-SBF solution was kept in an electric furnace at $37^{\circ} \mathrm{C}$ for 3 days, and $\mathrm{pH}$ of the solution was adjusted to $\mathrm{pH}$ 7.4.

Then the samples underwent alkali treatments to increase hydrophilicity and crystallinity, which was performed by immersing specimens in $100 \mathrm{~mL}$ of $1.0 \mathrm{~mol} \cdot \mathrm{L}^{-1} \mathrm{NaOH}$ aqueous solutions at $80^{\circ} \mathrm{C}$ for $2 \mathrm{~h}$ [18]. Finally, the specimens were washed with distilled water and dried in air.

Morphology of the samples was studied using field emission electron microscopy (FE-SEM, HitachiS4700, Japan). The chemical composition and phase purity of the coatings were characterized by energydispersive X-ray spectroscopy (EDX, RMAX energy EX-200, Horiba, Japan) and X-ray diffractometer (XRD; PANalytical, X'Pert PRO, Netherlands) with $\mathrm{Cu} \mathrm{K} \alpha$ radiation $(30 \mathrm{~mA}, 40 \mathrm{kV})$. The morphology and structure of the nano-crystallites formed in $\mathrm{m}$ SBF solution were examined by selected area electron diffraction (SAED) pattern and high resolution transmission electron microscopy (HRTEM; Technai-F20, Philips, Netherlands) operated at $200 \mathrm{kV}$. The TEM sample was prepared by dispersing powders in water and drying on a carbon-coated $\mathrm{Cu}$ grid. 
The presence of functional groups was confirmed by using Fourier transform infrared spectroscopy (Spectrum 400, PerkinElmer, UK) with an attenuated total reflectance (ATR) accessory. The Laser-Raman spectra of the calcium phosphate/chitosan samples were recorded in the spectral range of $100-4000 \mathrm{~cm}^{-1}$ using a Laser-Raman spectrometer (Jasco, NRS5100, USA), which employs a Ar-ion laser source with an excitation wavelength $532 \mathrm{~nm}$ and resolution of $1 \mathrm{~cm}^{-1}$ at $5.6 \mathrm{~mW}$ laser power.

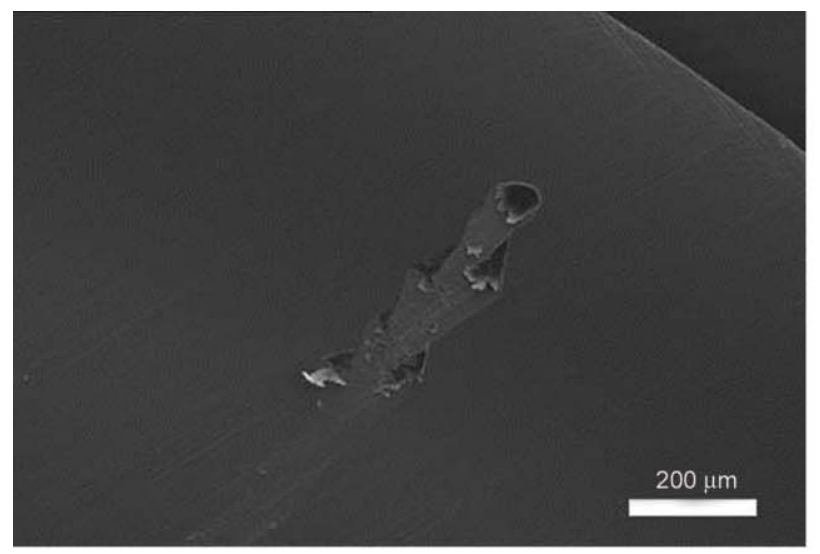

a)

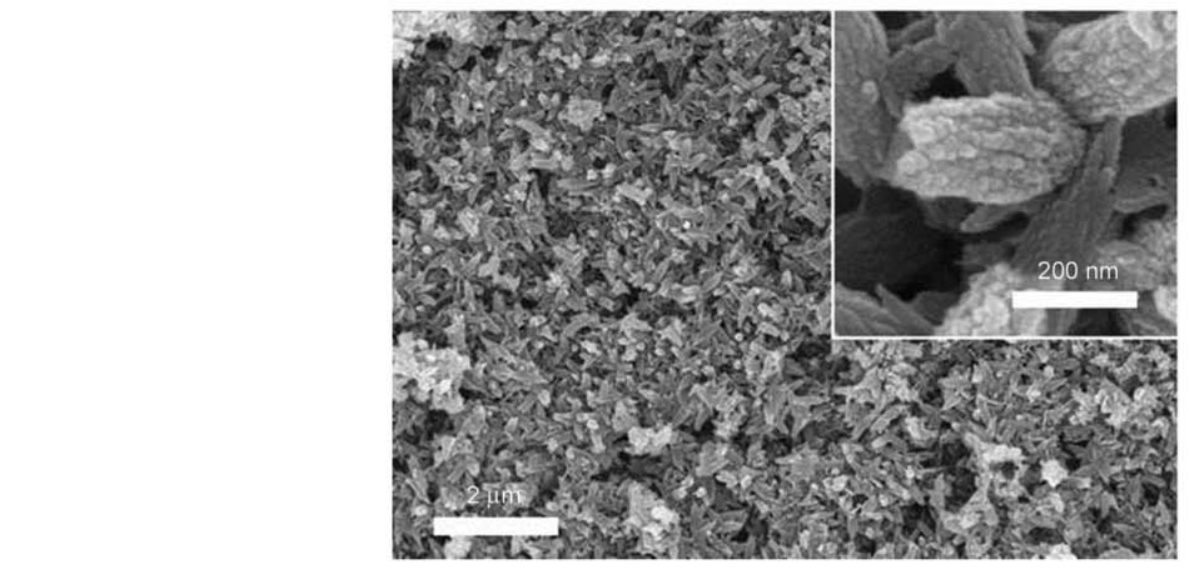

c)

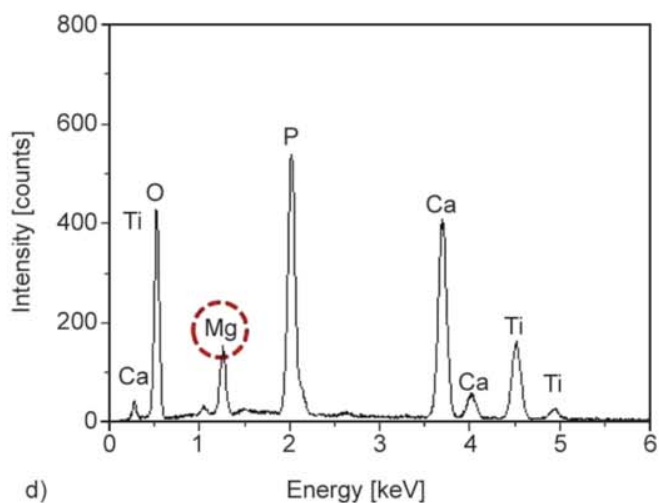

\section{Results and discussion}

b)

Figure 1a shows a photograph of CS coated Ti substrate. Figure $1 \mathrm{~b}$ shows typical features of precipitation of $\mathrm{CaP}$ after immersion in $\mathrm{m}-\mathrm{SBF}$ for 3 days. Precipitation started at individual granules on the CS-coated titanium substrate and the granules gradually grew together to form a dense layer on the specimen surface. It has been hypothesized that soaking in $\mathrm{m}$-SBF solution provides a supersaturation of $\mathrm{Ca}^{2+}$ ions around the CS-coated substrate through ionic
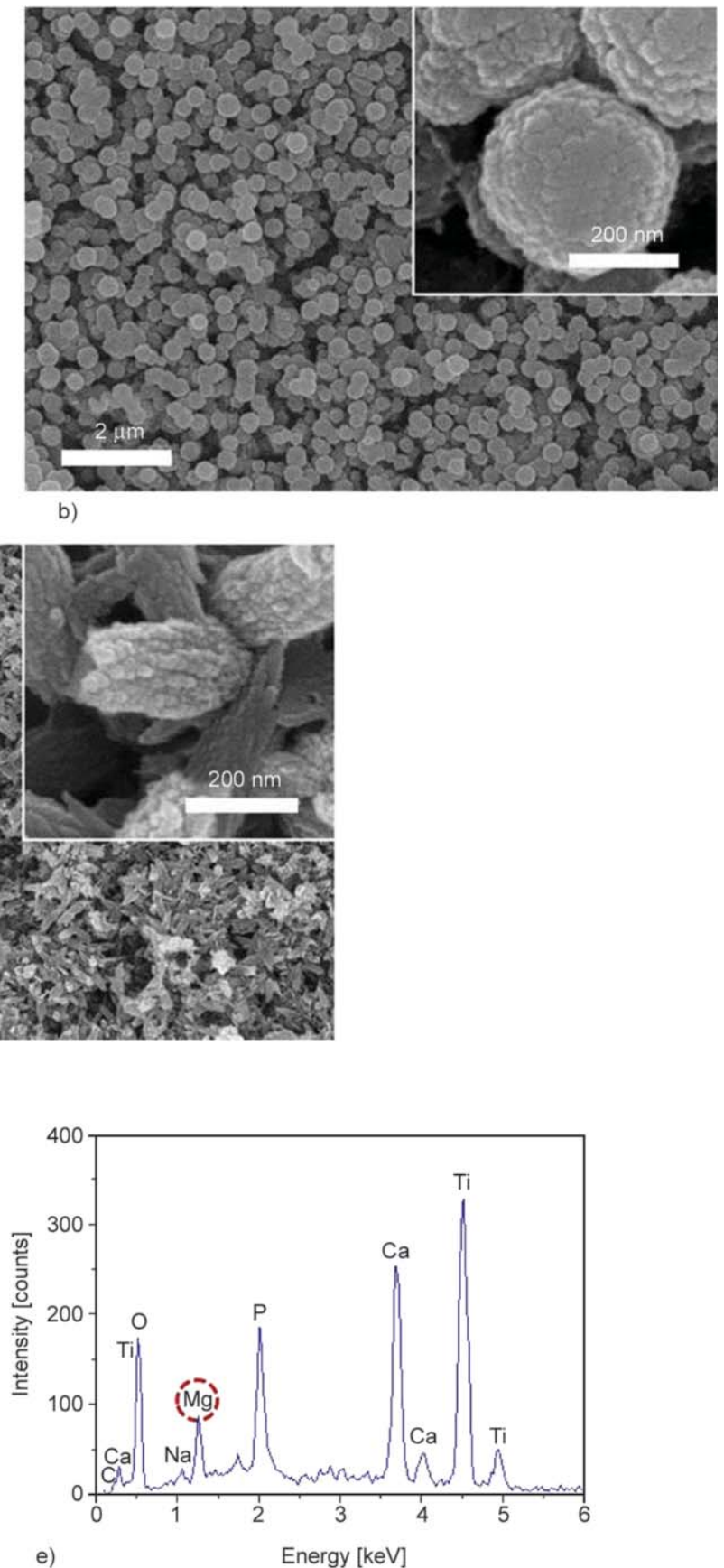

Figure 1. SEM image of spin coated Ti substrate (a), SEM images and EDX analysis of CaP/CS formed by immersion in $\mathrm{m}$ $\mathrm{SBF}$ solution for 3 days ( $\mathrm{b}$ and $\mathrm{d}$ ) and after post-NaOH treatment at $80^{\circ} \mathrm{C}$ for $2 \mathrm{~h}$ (c and e). Insets show the magnified portion of $\mathrm{CaP} / \mathrm{CS}$ samples. 
interactions between calcium ions and the negatively charged $\mathrm{OH}$ groups available on the polysaccharides. Then, the incorporated phosphate ions bind to calcium ions to form the initial nuclei. Once the $\mathrm{CaP}$ nuclei are formed, they grow by uptake of calcium and phosphate ions from the surrounding SBF [19]. High-magnification SEM images further revealed that each $\mathrm{CaP} / \mathrm{CS}$ granule consisted of a large number of spheres of $350 \mathrm{~nm}$ with $10 \mathrm{~nm}$-sized nanoparticles (Figure 1b). The spin coated-CS acts as a binder to keep the $\mathrm{CaP}$ compound at the implant site and contributes as a size controller of $\mathrm{CaP}$ formed in $\mathrm{m}$ SBF. After $1 \mathrm{M} \mathrm{NaOH}$ post-treatment of the $\mathrm{CaP} / \mathrm{CS}$ composite, samples showed a significant change in the surface morphology, showing ellipsoidal clusters of self-generated crystallites (grains) measuring $\sim 10 \mathrm{~nm}$ in size (Figure 1c). The EDX spectrum of the coating formed in the m-SBF solution showed high calcium, phosphate and titanium peaks, and low magnesium peak (Figure 1d). The $\mathrm{Ca} / \mathrm{P}$ ratio was only 1.32 , which is similar to that of the stoichiometric OCP. The EDS spectrum of the coating after post-

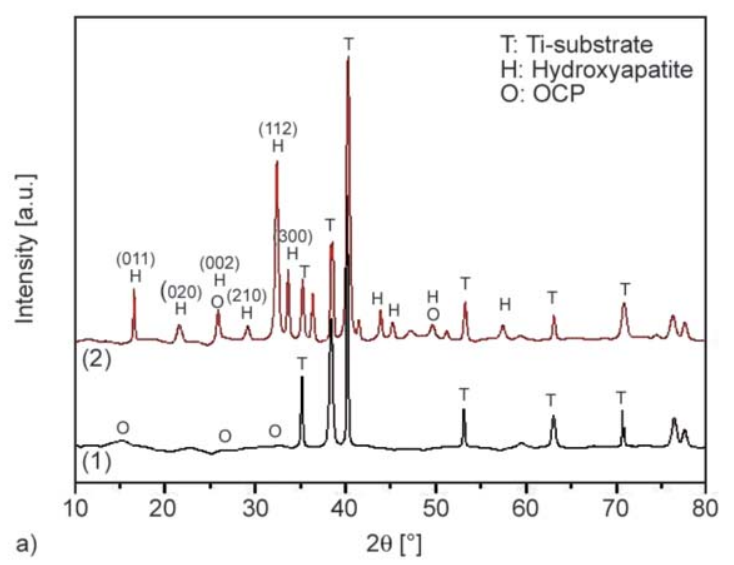

$\mathrm{NaOH}$ treatment showed similar calcium and titanium substrate peaks, but lower phosphate peaks, which suggests partial dissolution of the phosphate ions from the $\mathrm{CaP} / \mathrm{CS}$ coating. SEM-EDX analysis showed that the ellipsoidal apatite crystallites (in Figure 1e) were composed mainly of hydroxyapatite, and exhibited a $\mathrm{Ca} / \mathrm{P}$ molar ratio of 1.82 . Such a high $\mathrm{Ca} / \mathrm{P}$ ratio was ascribed to the presence of carbonate-apatite, in which the $\mathrm{CO}_{3}^{2-}$ had replaced $\mathrm{PO}_{4}^{3-}$ and $\mathrm{OH}^{-}$. The combined effects of calcium and magnesium are expected to accelerate the deposition of calcium phosphate for bone mineralization [20].

The XRD patterns of the $\mathrm{CaP} / \mathrm{CS}$ after soaking in $\mathrm{m}$ $\mathrm{SBF}$ and after post-NaOH treatment are shown in Figure 2a. The XRD pattern of the coatings (Figure $2 \mathrm{a}(1)$ ) exhibits three wide bands at approximately $2 \theta=16.2,26.0$ and $32.1^{\circ}$. The broadening of the diffraction peaks arose from poor crystallinity of the $\mathrm{CaP} / \mathrm{CS}$ coating, as also observed by SEM (Figure 1b). The position and intensities of these diffraction lines indicated an OCP structure. On the contrary, only two sharp peaks at $2 \theta=\sim 26$ and $\sim 32^{\circ}$

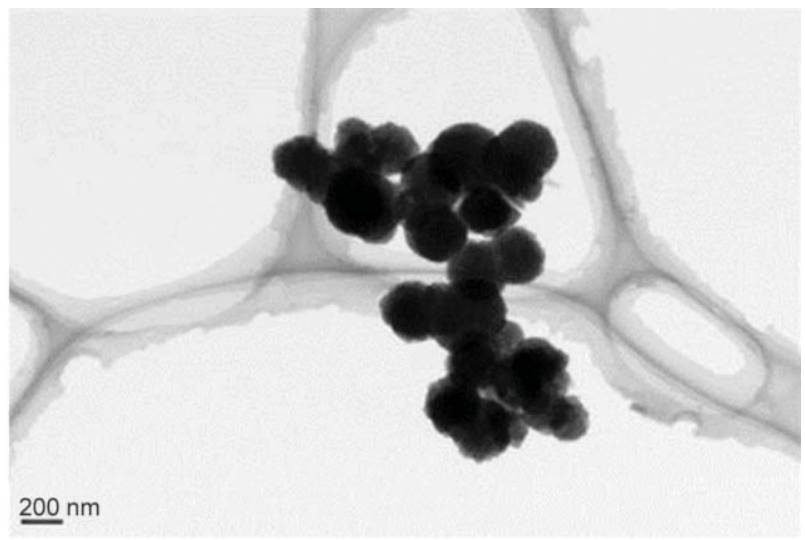

b)

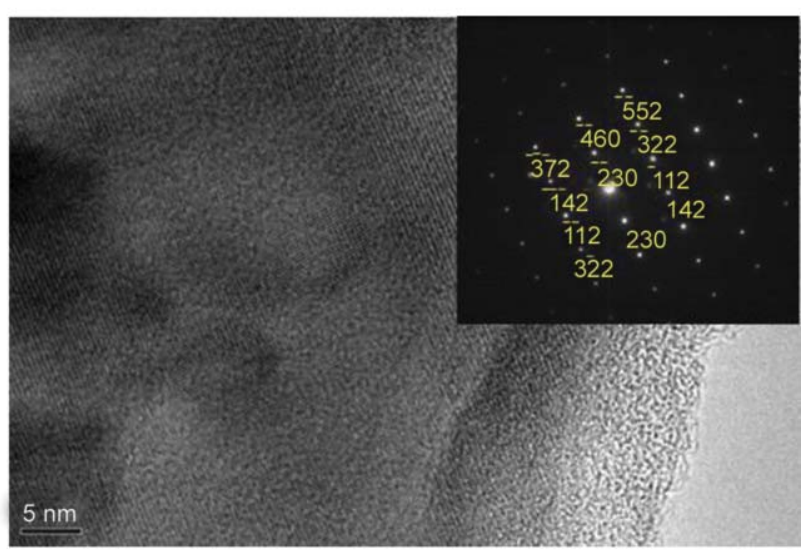

c)

Figure 2. (a) Thin film X-ray diffraction patterns of CaP/CS formed by immersion in m-SBF solution for 3 days (1) and after post-NaOH treatment at $80^{\circ} \mathrm{C}$ for $2 \mathrm{~h}(2)$. (b and c) TEM bright-field image and corresponding single diffraction pattern of $\mathrm{CaP} / \mathrm{CS}$ formed by immersion in $\mathrm{m}-\mathrm{SBF}$ solution for 3 days. 
were seen in the pattern presented in Figure $2 \mathrm{a}(2)$, and the peaks at $2 \theta=16.5,21.5,29.1,32.3$ and $32.9^{\circ}$ corresponded to the overlapping of (011), (020), (210), (112), and (300) diffraction peaks of HAp. Moreover, the peak at $2 \theta=25.7^{\circ}$, corresponding to the HAp (002) diffraction plane, indicated that $\mathrm{CaP} /$ CS composites consisted of HAp and OCP crystals. This result implies that the post- $\mathrm{NaOH}$ treatment plays a role as an accelerator of HAp crystallites after the growth of $\mathrm{CaP}$ crystallites in $\mathrm{m}-\mathrm{SBF}$ [21]. Crystals of the CaP from m-SBF was further assessed by TEM observation. Figure $2 b$ and $2 c$ show the typical TEM images and selected area electron diffraction (SAED) pattern of OCP crystals extracted from the $\mathrm{CaP} / \mathrm{CS}$ surfaces after immersion in $\mathrm{m}-\mathrm{SBF}$ for 3 days. Also, OCP was identified from the SAED pattern in TEM with $\mathrm{B}$ (beam direction) $=[110]($ Figure 2c).

Figure 3a displays the FT-IR spectra of the $\mathrm{CaP} / \mathrm{CS}$ coating formed in $\mathrm{m}-\mathrm{SBF}$ and then post- $\mathrm{NaOH}$ treated. In Figure $3 \mathrm{a}(1)$, the bands attributable to stretching and deformation of the $\mathrm{O}-\mathrm{H}$ group of water were observed at 3250 and $1604 \mathrm{~cm}^{-1}$, respectively. And, the peaks at 559 and $1030 \mathrm{~cm}^{-1}$ were attributed to the $\mathrm{HPO}_{4}$ band that originated from the OCP structure. The $\mathrm{P}-\mathrm{OH}$ band, characteristic of the $\mathrm{HPO}_{4}^{2-}$ group, was observed at $877 \mathrm{~cm}^{-1}$, confirming the presence of the OCP structure. Figure 3a(2) shows the FT-IR spectrum of the $\mathrm{CaP} / \mathrm{CS}$ coating on cp-Ti after post$\mathrm{NaOH}$ treatment. Absence of the band associated to the stretching mode of the $\mathrm{O}-\mathrm{H}$ group of water is worth noting. The band at $1410 \mathrm{~cm}^{-1}$ related to the $\mathrm{CO}_{3}^{2-}$ group, characterizing a carbonated hydroxyapatite, was also observed. The band at $1033 \mathrm{~cm}^{-1} 1$ was attributed to P-O stretching, whereas the bands

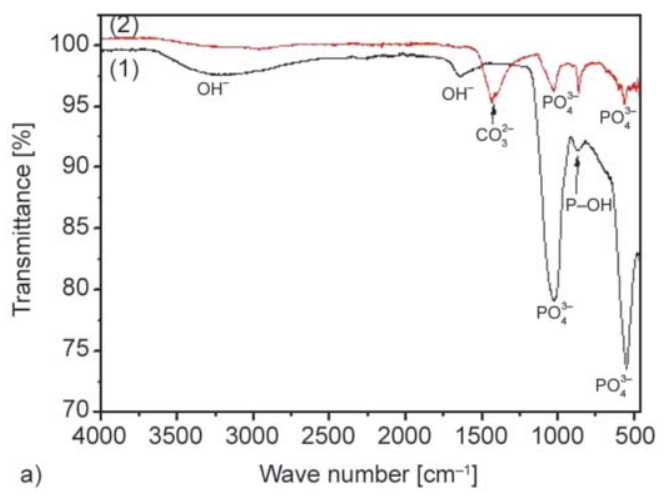

at 566 and $605 \mathrm{~cm}^{-1}$ were associated with deformation vibration of the $\mathrm{P}-\mathrm{O}$ in the $\mathrm{PO}_{4}$ group.

As shown in Figure 3b(1), in Raman spectrum after $\mathrm{m}$-SBF immersion, the $v 1$ vibration was resolved into a doublet with bands at 967 and $956 \mathrm{~cm}^{-1}$, which is characteristic of OCP. Bands in the OCP spectra attributable to $\mathrm{HPO}_{4}$ included that at $1074 \mathrm{~cm}^{-1}$ and weak bands at 962,588 and $436 \mathrm{~cm}^{-1}$. The Raman spectrum of OCP contained bands similar to those observed in the HAp spectra. In addition, for OCP, some changes in the $\mathrm{PO}_{4}(\mathrm{v} 4)$ band at $588 \mathrm{~cm}^{-1}$ relative to $593 \mathrm{~cm}^{-1}$ of HAp and a small shoulder at $436 \mathrm{~cm}^{-1}$ of the $v 2$ phosphate band have been assigned to $\mathrm{HPO}_{4}$ vibrational modes [22]. The Raman spectra of $\mathrm{CaP} / \mathrm{CS}$ coating in the post- $\mathrm{NaOH}$ treated specimen (Figure $3 \mathrm{~b}(2)$ ) were dominated by a strong band at around $960 \mathrm{~cm}^{-1}$ that is derived from the symmetric stretching mode $(v 1)$ of the phosphate group. In the spectrum, the bands at 420 and $593 \mathrm{~cm}^{-1}$ corresponded to the $v 2$ bending vibration and $v 4$ modes of the $\mathrm{PO}_{4}^{3-}$ group were displayed, respectively. A strong carbonate band was observed at $1072 \mathrm{~cm}^{-1}$. The $v 1$ of carbonate apatite overlapped one band of the $v 2$ of $\mathrm{PO}_{4}^{3-}$ due to bonded chain between $\mathrm{CS}$ and $\mathrm{CaP}$.

\section{Conclusions}

Biomimetic bone-like apatite including magnesium ion was successfully synthesized by incubating the CS-coated Ti in $\mathrm{m}-\mathrm{SBF}$ and following post- $\mathrm{NaOH}$ treatment. The $\mathrm{CS}$ acts as a binder to keep the $\mathrm{CaP}$ compound at the implant site and contributes as a size controller of $\mathrm{CaP}$ formed in $\mathrm{m}-\mathrm{SBF}$. Spontaneously formed HAp was tightly bonded to the substrates after post- $\mathrm{NaOH}$ treatment. One of the im-

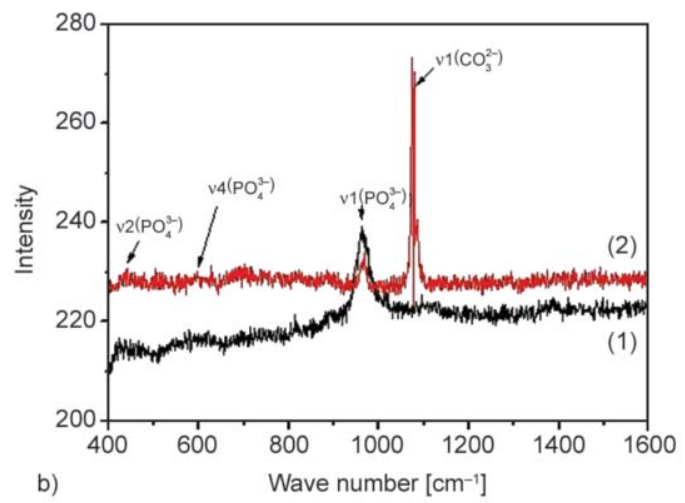

Figure 3. FT-IR spectra (a) and Raman spectra (b) of the CaP/CS film formed by immersion in m-SBF solution for 3 days (1) and by post- $\mathrm{NaOH}$ treatment at $80^{\circ} \mathrm{C}$ for $2 \mathrm{~h}(2)$ 
portant findings in this study is that OCP was formed on the $\mathrm{CaP} / \mathrm{CS}$ composite by immersion in $\mathrm{m}-\mathrm{SBF}$ within a very short time. In the FT-IR, XRD and SEM studies, the formation of carbonate apatite after post-NaOH treatment was confirmed. The obtained coatings are expected to provide corrosion protection of Ti and can be utilized for the fabrication of advanced biomedical implants.

\section{Acknowledgements}

This research was supported by the National Research Foundation of Korea (NRF) grant funded by the Korea government (MSIP) (No. 2011-0030121).

\section{References}

[1] Wopenka B., Pasteris J.: A mineralogical perspective on the apatite in bone. Materials Science and Engineering: C, 25, 131-143 (2005).

https://doi.org/10.1016/j.msec.2005.01.008

[2] Watanabe Y., Eryu H., Matsuura K.: Evaluation of threedimensional orientation of $\mathrm{Al}_{3} \mathrm{Ti}$ platelet in Al-based functionally graded materials fabricated by a centrifugal casting technique. Acta Materialia, 49, 775-783 (2001). https://doi.org/10.1016/S1359-6454(00)00384-0

[3] Itoh S., Kikuchi K., Takakuda K., Koyama Y., Matsumoto H. N., Ichinose S., Tanaka J., Kawauchi T., Shinomiya K.: The biocompatibility and osteoconductive activity of a novel hydroxyapatite/collagen composite biomaterial, and its function as a carrier of rhBMP-2. Journal of Biomedical Materials Research Part A, 54, 445-453 (2001).

https://doi.org/10.1002/10974636(20010305)54:3<445::AID-JBM190>3.0.CO;2-9

[4] Ficai A., Albu M. G., Birsan M., Sonmez M., Ficai D., Trandafir V., Andronescu E.: Collagen hydrolysate based collagen/hydroxyapatite composite materials. Journal of Molecular Structure, 1037, 154-159 (2013).

https://doi.org/10.1016/j.molstruc.2012.12.052

[5] Guo Y-P., Guan J-J., Yang J., Wang Y., Zhang C-Q., Ke Q-F.: Hybrid nanostructured hydroxyapatite-chitosan composite scaffold: Bioinspired fabrication, mechanical properties and biological properties. Journal of Materials Chemistry B, 3, 4679-4689 (2015).

https://doi.org/10.1039/C5TB00175G

[6] Barbani N., Guerra G. D., Cristallini C., Urciuoli P., Avvisati R., Sala A., Rosellini E.: Hydroxyapatite/gelatin/gellan sponges as nanocomposite scaffolds for bone reconstruction. Journal of Materials Science: Materials in Medicine, 23, 51-61 (2012).

https://doi.org/10.1007/s10856-011-4505-2
[7] Huang Y., Zhang X., Wu A., Xu H.: An injectable nanohydroxyapatite (n-HA)/glycol chitosan (G-CS)/hyaluronic acid (HyA) composite hydrogel for bone tissue engineering. RSC Advances, 6, 33529-33536 (2016). https://doi.org/10.1039/C5RA26160K

[8] Lynn A. K., Yannas L. V., Bonfield W.: Antigenicity and immunogenicity of collagen. Journal of Biomadical Materials Research Part B: Applied Biomaterials, 71B, 343-354 (2004).

https://doi.org/10.1002/jbm.b.30096

[9] Phisalaphong M., Jatupaiboon N., Kingkaew J.: Biosynthesis of cellulose-chitosan composite. in 'Chitin, chitosan, oligosaccharides and their derivatives: Biological activities and applications' (ed.: Kim S-K.) CRC Press, New York, 53-65 (2011).

[10] Song L., Gan L., Xiao Y-F., Wu Y., Wu F., Gu Z-W.: Antibacterial hydroxyapatite/chitosan complex coatings with superior osteoblastic cell response. Materials Letters, 65, 974-977 (2011).

https://doi.org/10.1016/j.matlet.2010.12.051

[11] Lluch A. V., Ferrer G. G., Pradas M. M.: Biomimetic apatite coating on $\mathrm{P}\left(\mathrm{EMA}\right.$-co-HEA) $/ \mathrm{SiO}_{2}$ hybrid nanocomposites. Polymer, 50, 2874-2884 (2009).

https://doi.org/10.1016/j.polymer.2009.04.022

[12] Kokubo T., Takadama H.: How useful is SBF in predicting in vivo bone bioactivity? Biomaterials, 27, $2907-$ 2915 (2006). https://doi.org/10.1016/j.biomaterials.2006.01.017

[13] Oliveira A. L., Costa S. A., Sousa R. A., Reis R. L.: Nucleation and growth of biomimetic apatite layers on $3 \mathrm{D}$ plotted biodegradable polymeric scaffolds: Effect of static and dynamic coating conditions. Acta Biomaterialia, 5, 1626-1638 (2009).

https://doi.org/10.1016/j.actbio.2008.12.009

[14] Tachaboonyakiat W., Serizawa T., Akashi M.: Inorganic-organic polymer hybrid scaffold for tissue engineering - II: Partial enzymatic degradation of hydroxyapatite-chitosan hybrid. Journal of Biomaterials Science, Polymer Edition, 13, 1021-1032 (2002). https://doi.org/10.1163/156856202760319162

[15] Granja P. L., Silva A. I. N., Borges J. P., Barrias C. C., Amaral I. F.: Preparation and characterization of injectable chitosan-hydroxyapatite microspheres. Key Engineering Materials, 254-256, 573-576 (2004).

https://doi.org/10.4028/www.scientific.net/KEM.254-256.573

[16] Muzzarelli C., Muzzarelli R. A. A.: Natural and artificial chitosan-inorganic composites. Journal of Inorganic Biochemistry, 92, 89-94 (2002). https://doi.org/10.1016/S0162-0134(02)00486-5

[17] Song H-J., Park Y-J., Moon W-J., Luong L. N., Kohn D. H.: Effects of protein-simulated body fluid mixing methods on characteristics of bone-like mineral. Materials Science and Engineering: C, 32, 2501-2507 (2012). https://doi.org/10.1016/j.msec.2012.07.032 
[18] Kim H-M., Kokubo T., Fujibayashi S., Nishiguchi S., Nakamura T.: Bioactive macroporous titanium surface layer on titanium substrate. Journal of Biomedical Materials Research Part A, 52, 553-557 (2000).

https://doi.org/10.1002/10974636(20001205)52:3<553::AID-JBM14>3.0.CO;2-X

[19] Ge H., Zhao B., Lai Y., Hu X., Zhang D., Hu K.: From crabshell to chitosan-hydroxyapatite composite material via a biomorphic mineralization synthesis method. Journal of Materials Science: Materials in Medicine, 21, 1781-1787 (2010). https://doi.org/10.1007/s10856-010-4045-1
[20] Bonucci E., Silvestrini G., Bianco P.: Extracellular alkaline phosphatase activity in mineralizing matrices of cartilage and bone: Ultrastructural localization using a cerium-based method. Histochemistry, 97, 323-327 (1992). https://doi.org/10.1007/BF00270033

[21] Lu X., Leng Y.: TEM study of calcium phosphate precipitation on bioactive titanium surfaces. Biomaterials, 25, 1779-1786 (2004).

https://doi.org/10.1016/j.biomaterials.2003.08.028

[22] Koutsopoulos S.: Synthesis and characterization of hydroxyapatite crystals: A review study on the analytical methods. Journal of Biomedical Materials Research Part A, 62, 600-612 (2002).

https://doi.org/10.1002/jbm.10280 